ARTICLE

https://doi.org/10.1038/s41467-019-14071-8

\title{
Formation of bridgmanite-enriched layer at the top lower-mantle during magma ocean solidification
}

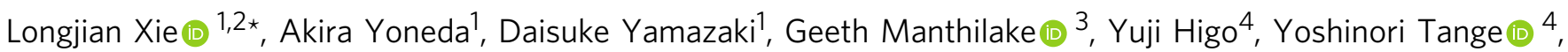
Nicolas Guignot ${ }^{5}$, Andrew King ${ }^{5}$, Mario Scheel ${ }^{5} \&$ Denis Andrault (i) ${ }^{3}$

Thermochemical heterogeneities detected today in the Earth's mantle could arise from ongoing partial melting in different mantle regions. A major open question, however, is the level of chemical stratification inherited from an early magma-ocean (MO) solidification. Here we show that the $\mathrm{MO}$ crystallized homogeneously in the deep mantle, but with chemical fractionation at depths around $1000 \mathrm{~km}$ and in the upper mantle. Our arguments are based on accurate measurements of the viscosity of melts with forsterite, enstatite and diopside compositions up to $\sim 30 \mathrm{GPa}$ and more than $3000 \mathrm{~K}$ at synchrotron $\mathrm{X}$-ray facilities. Fractional solidification would induce the formation of a bridgmanite-enriched layer at $1000 \mathrm{~km}$ depth. This layer may have resisted to mantle mixing by convection and cause the reported viscosity peak and anomalous dynamic impedance. On the other hand, fractional solidification in the upper mantle would have favored the formation of the first crust.

\footnotetext{
${ }^{1}$ Institute for Planetary Materials, Okayama University, Misasa, Tottori 682-0193, Japan. ${ }^{2}$ Bayerisches Geoinstitut, University of Bayreuth, 95440
} Bayreuth, Germany. ${ }^{3}$ Laboratoire Magmas et Volcans, Université Clermont Auvergne, CNRS, IRD, OPGC, F-63000 Clermont-Ferrand, France. ${ }^{4}$ Japan Synchrotron Radiation Research Institute, 1-1-1 Kouto, Sayo, Hyogo 689-5198, Japan. ${ }^{5}$ Synchrotron SOLEIL, Gif-sur-Yvette, France. *email: ddtuteng@gmail.com 
$\mathrm{T}$ he possibility that a magma-ocean (MO) induced a primordial chemical stratification has major implications for the mantle state and its dynamics over the Earth's history. For example, it could have induced large-scale provinces atop the core-mantle boundary ${ }^{1}$ or a basal MO that would have taken several billion years $(\mathrm{Ga})$ to crystallize ${ }^{2}$. There are geochemical arguments for the persistence of primitive reservoirs, based on the isotopic composition of rare gases in some oceanic island basaltseg3 and isotopic differences between the available mantle sources and various chondritic components ${ }^{4}$. The geochemical arguments, however, remain subject to discussions and may be insufficient to refine the complete scenario of $\mathrm{MO}$ crystallization.

The mechanism of MO crystallization has been modeled in the past and a key parameter, besides the global cooling rate, appears to be the vertical profile of melt viscosity ${ }^{5}$. Unfortunately, available experimental data are limited to $13 \mathrm{GPa}$ and $2500 \mathrm{~K}$ and the first-principles and empirical molecular dynamics simulations present a large discrepancy. For example, viscosities differing by a factor of 50 were reported at the lowermost-mantle P-T conditions of $120 \mathrm{GPa}$ and $4000 \mathrm{~K}^{6,7}$. First-principles molecular dynamics (FPMD) calculations should be more robust than empirical molecular dynamics simulations, because of absence of assumption about the charge density. They provide viscosity values within a factor of 2 or 3 of experimental data obtained at low pressures and may have an advantage for simulations at very high pressures ${ }^{7-9}$. However, experimental measurements are critically needed to confirm calculations and refine viscosity values, especially at lower mantle P-T conditions.

In this study, we measure viscosity of melts with forsterite, enstatite, and diopside compositions up to $\sim 30 \mathrm{GPa}$ by in-situ falling sphere viscometry. The viscosity of silicate melts shows complex pressure dependence at least up to $30 \mathrm{GPa}$. With the measured viscosity, we model the mechanism of the MO solidification. It suggests the formation of a bridgmanite-enriched layer at the top of the lower mantle upon MO cooling.

\section{Results and discussions}

Experimental conditions. We performed in-situ falling sphere viscometry in a multi-anvil apparatus coupled with intense X-ray beams generated by the SPring- 8 and Source optimisée de lumière d'énergie intermédiaire (SOLEIL) third generation synchrotron sources (see Methods section). We used a relatively large beam (about $2 \times 2 \mathrm{~mm}$ ) to record the falling path of a small rhenium sphere in the liquid silicate using an ultra-fast camera (Fig. 1), and a collimated beam $(50 \times 200 \mu \mathrm{m})$ to characterize the sample mineralogy and determine the pressure by X-ray diffraction. The complete fall through the $\sim 1 \mathrm{~mm}$ long sample is achieved in less than $1 \mathrm{~s}$, which is sufficiently short to avoid the chemical reaction between the Re-sphere and the molten silicate (Fig. 1c). The falling-sphere terminal velocity yields the melt viscosity based on the Stokes' law (see Methods section).

Major limitations encountered in previous works of the same type were technical difficulties to perform the ultrahigh temperatures (more than $\sim 2500 \mathrm{~K}$ ) that required to melt the silicate phases entirely and the difficulties to measure the extremely low viscosity of silicate melts at high pressure, requiring very fast radiographic measurements ${ }^{10-12}$. By using a new type of furnace made of boron-doped diamond ${ }^{13}$ and ultrafast camera (frame rate reaches $1000 \mathrm{f} / \mathrm{s}$ ), we could perform viscosity measurements up to $30 \mathrm{GPa}$ and $3250 \mathrm{~K}$. We investigated the viscosity of melts with compositions similar to major mantle minerals, namely forsterite $\left(\mathrm{Mg}_{2} \mathrm{SiO}_{4}, \mathrm{Fo}\right)$, enstatite $\left(\mathrm{MgSiO}_{3}, \mathrm{En}\right)$, and diopside $\left(\mathrm{CaMgSi}_{2} \mathrm{O}_{6}, \mathrm{Di}\right)$. Measurements have been performed slightly above the melting temperatures (see Methods section, Supplementary Table 1).
Viscosity measurements and modeling. Our new results fall in good agreement with previous works ${ }^{10,12,14-16}$ performed at lower pressures (Fig. 2). Along the liquidus, viscosities present a complex evolution with pressure for the three difference liquid compositions investigated. Viscosity is a thermally activated process that can be modeled based on the Arrhenius equation. Because our measurements were all performed at temperatures relatively close to the liquidus, we first assume an activation process against a dimensionless temperature, which is obtained by normalizing the experimental temperature to the melting temperature of the specimens at a given pressure:

$$
\eta(P, T)=\eta_{0} \exp \left(\frac{E_{a}(P)}{k T}\right)=\eta_{0} \exp \left(\frac{E_{a}^{*}(P)}{\left(T / T_{m}\right)}\right)=\eta_{0} \exp \left(\frac{E_{a}^{*}(P)}{T^{*}}\right)
$$

where $\eta_{0}$ is a scaling factor; $k$ Boltzmann constant; $T$ absolute temperature; $P$ pressure, $T_{\mathrm{m}}$ melting temperature at pressure $P ; E_{\mathrm{a}}$ activation enthalpy; $T^{*}$ dimensionless temperature $\left(T / T_{\mathrm{m}}\right) ; E_{\mathrm{a}}^{*}$ dimensionless form of the activation energy. At the liquidus temperature, $T^{*}$ equals 1 and we obtain:

$$
\ln (\eta)=\ln \left(\eta_{0}\right)+E_{a}^{*}(P)
$$

An accurate pressure dependence of $E_{\mathrm{a}}^{*}$ can be determined based on the viscosity profile along the liquidus (Fig. 2). Our viscosity data for Fo, En, and Di melt compositions suggest that the pressure dependence of $E_{\mathrm{a}}^{*}$ can be fitted using third order polynomial fit, at least up to $30 \mathrm{GPa}$ (Supplementary Table 3, Supplementary Fig. 5):

$$
\eta(P, T)=\eta_{0} \exp \left(\frac{c_{0}+c_{1} P+c_{2} P^{2}+c_{3} P^{3}}{T^{*}}\right)
$$

We note that the viscosity profiles can also be fitted using two linear sections (Supplementary Fig. 2, Supplementary Table 3). Based on Eq. (3), we can now recalculate the viscosity of the endmember melts at any temperatures and, in particular, along isotherms.

All of Fo, En, and Di compositions show a weak and complex pressure dependence along isotherms (Fig. 2). Our experimental results are quite consistent (within one order of magnitude) with FPMD predictions, especially for En and Fo composition (Fig. 2). Our results for $\mathrm{Di}$ are also consistent with experimental determinations of oxygen and silicon self-diffusions in Di melt ${ }^{17}$. En melt and, to a lesser extent, Di melt show a negative pressure dependence in some pressure ranges. Such an anomalous behavior was also reported in a basalt and another silicate melt ${ }^{18}$, based on both FPMD simulation ${ }^{19}$ and experimental measurements ${ }^{20,21}$. The negative pressure dependence is due to either the $\mathrm{Si}-\mathrm{O}$ bond weakening by the pressure-induced bending of the $\mathrm{Si}-\mathrm{O}-\mathrm{Si}$ angle ${ }^{21,22}$ or possibly the increasing concentration of five-fold $\mathrm{Si}-\mathrm{O}$ coordination species ${ }^{23,24}$. The complex pressure dependence correlates nicely with the mechanisms of silicate melt densification described previously) 22,25 (details in Supplementary Note 1 and Supplementary Fig. 4).

Extrapolation of melt viscosity to deep lower mantle conditions. The knowledge of the dependence of the melt viscosity along mantle isotherms enables the refinement of the true activation enthalpy and its pressure dependence $\left(E_{\mathrm{a}}\right.$ in Eq. (1); Supplementary Fig. 5). The refined $E_{\mathrm{a}}$ values at room pressure are $100 \pm 20$ and $159 \pm 10 \mathrm{~kJ} \mathrm{~mol}^{-1}$ for Fo, and En melts, respectively, in agreement with previous FPMD predictions ${ }^{7,8}$. Di melt presents a relative large $E_{a}\left(230 \pm 30 \mathrm{~kJ} \mathrm{~mol}^{-1}\right)$, which is consistent with diffusion experiments $\left(268 \mathrm{~kJ} \mathrm{~mol}^{-1}\right)^{17}$ but larger than FPMD prediction $\left(148 \pm 5 \mathrm{~kJ} \mathrm{~mol}^{-1}\right)^{9}$. Further work is needed to solve 
a $1200 \mathrm{~ms} 1300 \mathrm{~ms} 1400 \mathrm{~ms} 1500 \mathrm{~ms} 1600 \mathrm{~ms}$
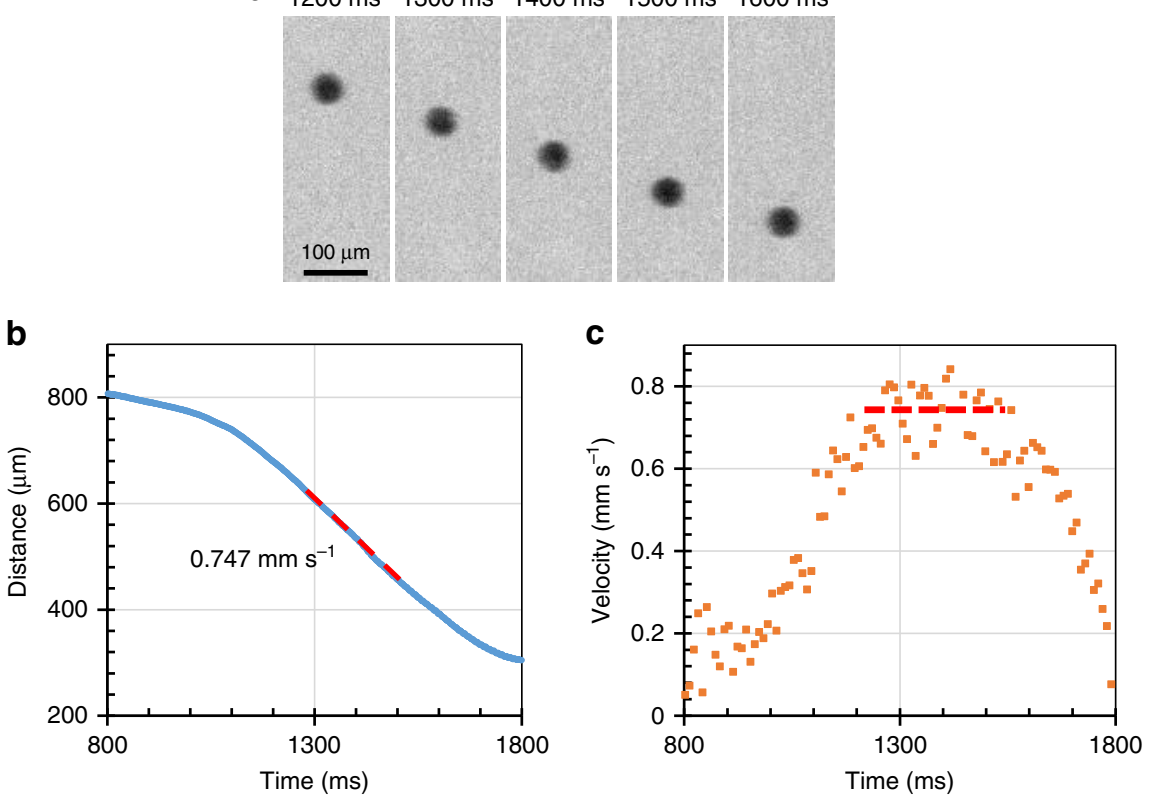

Fig. 1 Experimental observation of the falling sphere. a Sequential radiographic images recorded at $\sim 24 \mathrm{GPa}$ and $\sim 2873 \mathrm{~K}$ during the fall of a Re-sphere of $\sim 65 \mu \mathrm{m}$ diameter (Run MA24). b Position of the sphere as a function of time in Run MA24. The sphere position was fitted by a Gaussian function in each $\mathrm{X}$-ray radiographic image (blue symbol). The melt viscosity can be calculated from the terminal velocity (red dashed line) using Eq. (4). c Velocity/time plot of the sphere in Run MA24, using a sampling time of $10 \mathrm{~ms}$. The red dashed line is a best fit through the data points located on the "velocity plateau" corresponding to the terminal velocity.
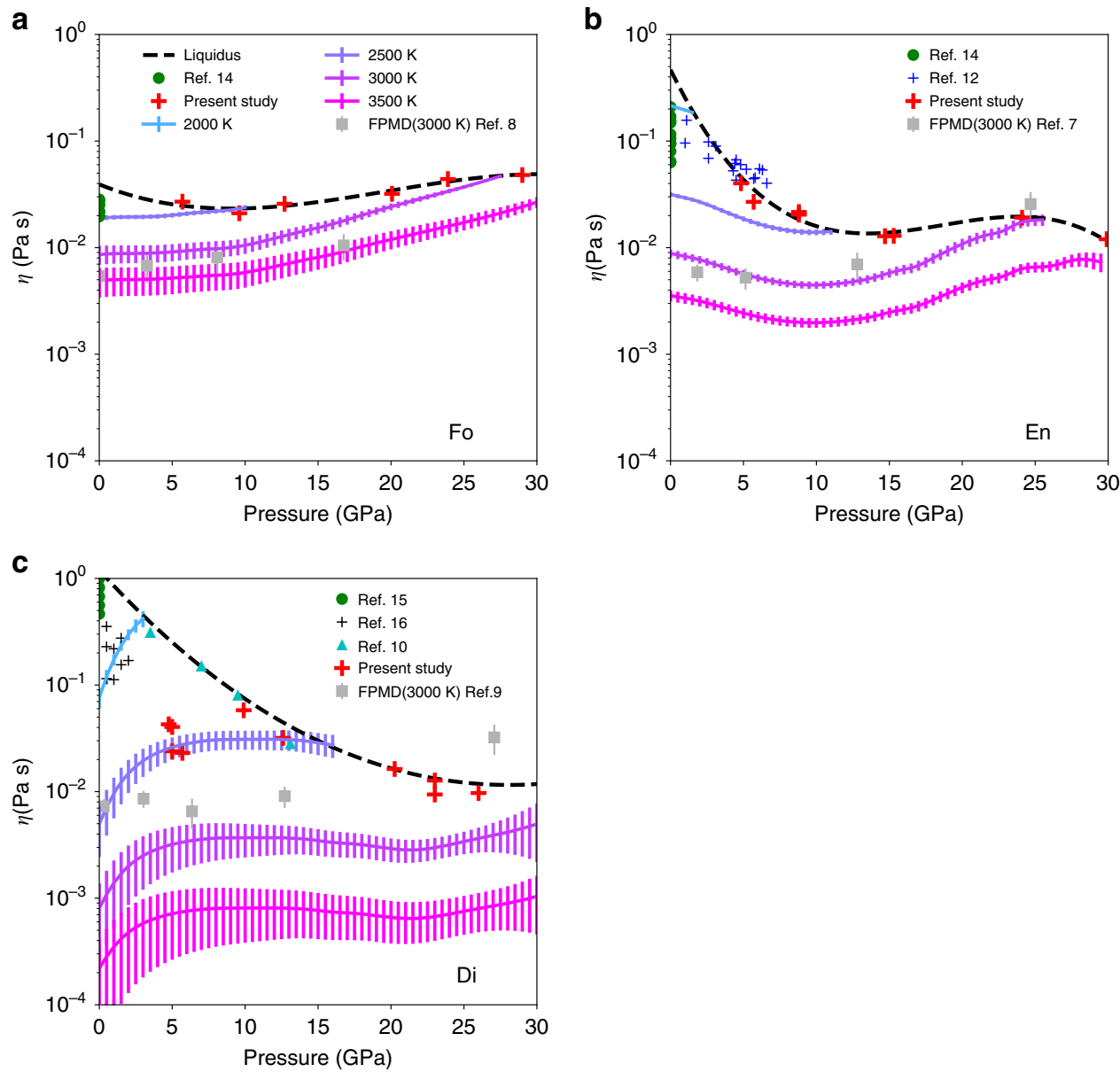

Fig. 2 Viscosities of silicate melts under pressure. a-c Fo, En, and Di composition, respectively. We report our experimental data as red crosses, whose temperatures are shown in Supplementary Fig. 2 and Supplementary Table. 1. Dashed black lines are viscosities along liquidus. Colored lines are viscosities recalculated along isotherms with their $1 \sigma$ standard deviation. 
Table 1 Model for the activation enthalpy (Supplementary Fig. 5).

\begin{tabular}{lccc} 
Composition & $\eta_{\mathbf{o}}$ (Pa s) & $\boldsymbol{a}\left(\mathbf{k J ~} \mathbf{~ m o l}^{-\mathbf{1}} \mathbf{~ G P a}^{-\mathbf{1}}\right)$ & $\boldsymbol{b}\left(\mathbf{k J ~} \mathbf{~ m o l}^{-\mathbf{1}}\right)$ \\
\hline $\mathrm{Mg}_{2} \mathrm{SiO}_{4}$ & $2.3(12) \times 10^{-4}$ & $1.64(7)$ & $90(1)$ \\
$\mathrm{MgSiO}_{3}$ & $7.63(484) \times 10^{-5}$ & $1.14(19)$ & $141(3)$ \\
$\mathrm{CaMgSi}_{2} \mathrm{O}_{6}$ & $3.17(685) \times 10^{-8}$ & $0.49(16)$ & $253(3)$ \\
\hline
\end{tabular}

this discrepancy. However, it will not affect the conclusion of this article significantly because the amount of diopside is less than $2 \%$ in relevant mantle compositions (Supplementary Table 4) and only extrapolations to the highest mantle pressures could be affected by significant uncertainties, while viscosity at moderate pressures are satisfactorily constrained by the present results.

Linear fits (Table 1) enable the extrapolation of the melts viscosity towards the very deep mantle using the Arrhenius equation $\left(\eta(P, T)=\eta_{0} \exp \left((a P+b) / T^{*}\right)\right.$. They average the complex pressure-dependence of viscosity at low pressures. Still, the fitted $E_{\mathrm{a}}$ values remain within $10 \%$ of the experimental $E_{\mathrm{a}}$ (Supplementary Fig. 5).

Viscosity of magma ocean. To estimate the viscosity of silicate melts with compositions relevant to the deep mantle, we now apply the Adam-Gibbs mixing theory. It states that the logarithm viscosity of a complex system can be expressed well as a linear combination of logarithm of the viscosities of end-members ${ }^{26}$ (Eq. (10) in Methods section). Thus, we used end-member melts of Fo, En, $\mathrm{Di}$, and anorthite $\left(\mathrm{An}, \mathrm{CaAl}_{2} \mathrm{Si}_{2} \mathrm{O}_{8}\right)^{27}$ to calculate the viscosity, and its dependence with pressure and temperature, of MOs consisting of peridotitic KLB-1 and chondritic-type compositions (Supplementary Table 4). Because water has little effect on a completely depolymerized, high temperature magma viscosity ${ }^{28,29}$, we only consider dry MOs. For more accuracy, the pressure-dependence can be modeled using either experimental constraints (Fig. 2) or Ahrenius fits (Supplementary Fig. 5), for lower and higher than $30 \mathrm{GPa}$, respectively. It appears that the MO viscosity is controlled by its two main chemical components: Fo and En. Our calculations for KLB-1 composition (Fig. 3a) is roughly compatible with available measurements ${ }^{30}$. Interestingly, viscosity profiles present a local minimum at depths around $300-400 \mathrm{~km}$ along MO adiabats and a local maximum at $\sim 660$ $\mathrm{km}$ along the liquidus. Also, the viscosity of KLB-1 is found to be slightly lower than that of the chondritic mantle along their respective liquidus temperatures.

Major parameters for modeling of magma ocean solidification. Before a MO behaves like a solid at a crystal fraction higher than $\sim 60 \%{ }^{31}$, the progressive crystallization could have induced some fractional crystallization. Its occurrence, or not, depends on the competition between the forces favoring the gravitational sedimentation or the suspension of the solid grains in a turbulently convective $\mathrm{MO}^{5}$. Above a critical diameter, crystals precipitate at the bottom of the MO. Therefore, the value of crystal/critical diameter ratio (Rcc, see Methods section) is an indicator on whether the MO crystallization occurs with fractional solidification $(\mathrm{Rcc}>1)$ or at chemical equilibrium $(\mathrm{Rcc}<1)$. Fractional solidification is favored by low MO viscosity, low heat flux and large density contrast between crystals and melt.

To model the mechanism of MO solidification, it is necessary to determine the change of Rcc value during MO cooling. For this, preliminary definitions are needed. We define the MObottom as the higher mantle depth where the rheological transition $\left(T_{\text {Rheo }}\right)$ already occurred upon MO cooling (see Methods section). The MO-bottom defines the temperature profile in the entire MO, based on the $T_{\text {Rheo }}$ anchor point coupled to the adiabatic temperature gradient in the MO. The calculated potential surface temperature is used to determine the heat flux through the MO, considering loss of heat by thermal radiation (Supplementary Fig. 7a, b). Then, we define the crystallization zone as the range of mantle depths where solid and melt coexist. This region extends from the MO-bottom to the shallower intersection between the adiabatic temperature gradient in the mushy zone and the liquidus profile. Significant uncertainties remain about its thickness, because of the effect of the latent heat of fusion on the adiabatic temperature gradient between the solidus and the liquidus. We consider different assumptions for its thickness below. In all cases, we calculate an averaged melt viscosity and an averaged solid-melt density contrast within the crystallization zone.

To model the solid-melt density contrast, we consider a range of Fe solid-liquid partition coefficient $\left(K_{\mathrm{Fe}}\right)$ from 0.2 to 0.6 (see ref. 32 and references therein) and first liquidus phases that change with $\mathrm{MO}$ depth (see Methods section). Higher $K_{\mathrm{Fe}}$ favors higher density contrast of bridgmanite over liquid. Upon MO crystallization, the averaged density contrast first increases due to higher bridgmanite density, compared to the melt (Supplementary Fig. 8e, f). Then, it decreases above $\sim 1500 \mathrm{~km}$ when, within the upper part of the crystallization zone, the first liquidus phase changes from bridgmanite to majorite at $\sim 660 \mathrm{~km}$ and majorite to olivine at $\sim 450 \mathrm{~km}$. It finally increases again at low MO-bottom depth, due to high olivine density at shallow mantle depth. These variations cause a peak and a valley at $\sim 1500 \mathrm{~km}$ and $\sim 450$ depths, respectively.

As long as a MO remains fully molten at shallow mantle depth, crystals experience a life cycle of nucleation-growthdissolution due to turbulent vertical convection. With a short residence time of about one week in the crystallization zone ${ }^{5}$, grain growth is insignificant and crystal size is controlled by nucleation processes. Later, the crystallization zone reaches the Earth's surface, that is, the whole MO is the crystallization zone, making the crystal lifetime considerably longer. Some grains can survive and grow until the MO is entirely solidified. In this regime, crystal size is controlled by grain growth (Ostwald ripening, see Methods section). The depth when the controlling mechanism switches, depends on the definition of the crystallization zone before the fully molten layer disappeared. To check the robustness of our conclusions, we considered three different situations: the crystallization zone extends (1) in the entire MO, (2) up to $1000 \mathrm{~km}$ above the MO bottom, and (3) up to the intersection between the MO liquidus and the adiabatic temperature profile, neglecting the role of the latent heat of fusion. Within these three assumptions, Ostwald ripening increases the grain size significantly from the onset of MO solidification, when the MO-bottom reaches $1000 \mathrm{~km}$ depth (in agreement with previous reports considering the latent heat of fusion within the crystallizing zone $\mathrm{e}^{33}$ ) and when the MO bottom reaches $\sim 700$ (peridotitic MO) or $\sim 150 \mathrm{~km}$ (chondritic-type MO) depths, for situations 1,2 , and 3, respectively. To enforce the robustness of our conclusion, we also calculated Rcc value without any grain growth. In reality, the mechanism of MO cooling should be close to situation (2).

Mechanisms of magma ocean solidification. We now model the progressive cooling of a MO with an initial depth of $2900 \mathrm{~km}$, as possibly occurred on Earth after the major Moon Forming Impact $^{34}$. We based our discussion on the Rcc value, which indicates a high probability of fractional solidification when it becomes higher than unity. For a chondritic-type MO, Rcc value is found larger than unity in a range of depths around $1000 \mathrm{~km}$ 

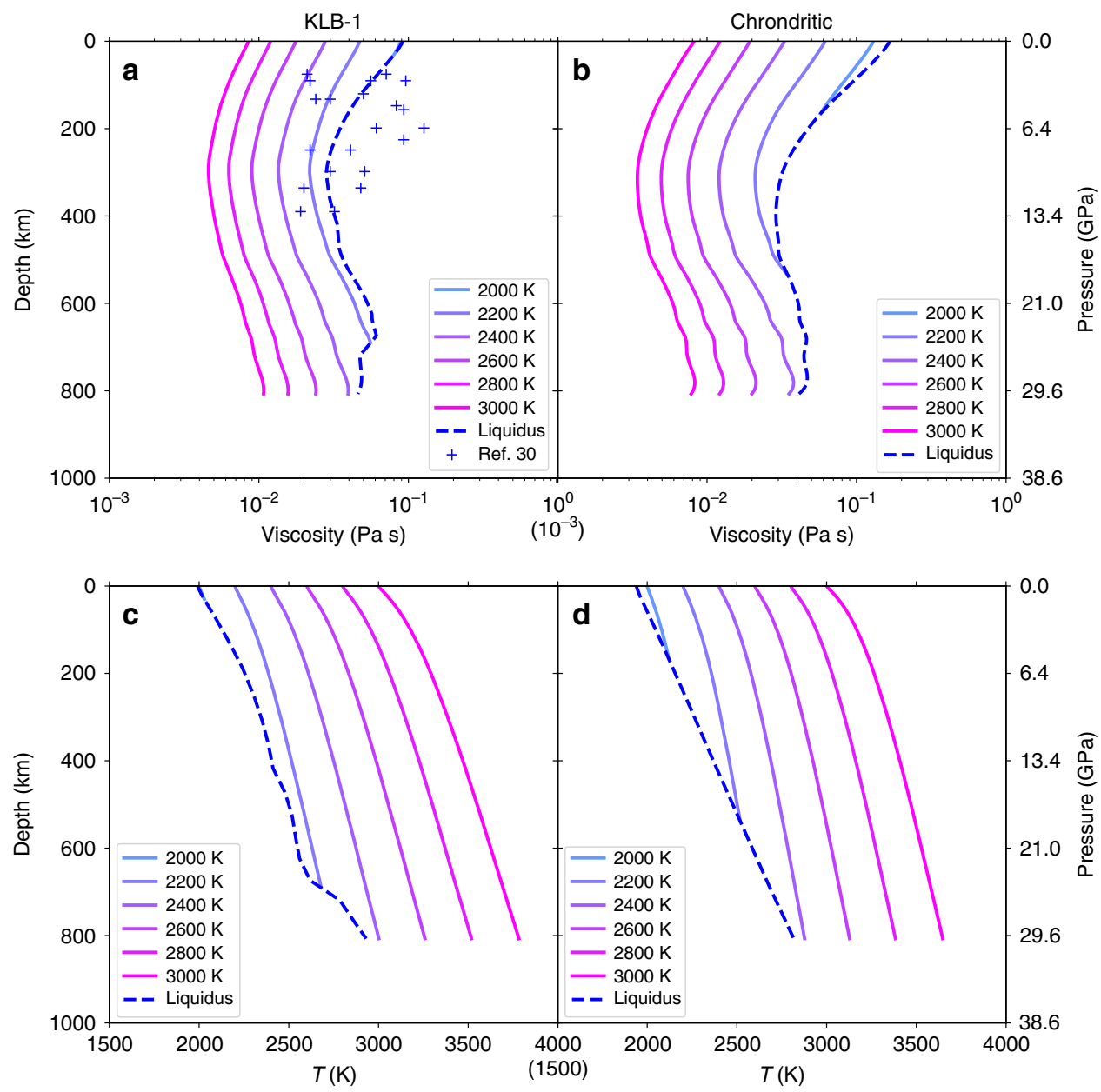

Fig. 3 Change of magma ocean viscosity with depth. $\mathbf{a}$, b We report MO viscosities with KLB-1 (left) and chondrite-type (right) compositions for potential surface temperatures from 2000 to 3000 K. Solid and dashed lines are calculated along mantle adiabats and liquidus profiles, respectively. c, d Solid and dashed lines represent adiabatic ${ }^{63}$ and liquidus ${ }^{55,56}$ profiles, respectively, for molten KLB-1 and chondrite-type mantle compositions.

depth (Fig. 4) even when using the less favorable parameters of $K_{\mathrm{Fe}}$ equal 0.2 and a maximum $\mathrm{MO}$ heat flux, thus ignoring the possible impact of a blanketing atmosphere (Supplementary Fig. 11b). For KLB-1 composition, fractional solidification would also occur around similar depth regardless of the value of $K_{\mathrm{Fe}}$, if the blanketing effect is larger than $20 \%\left(C_{\mathrm{f}}\right.$ smaller than 0.8$)$ (Fig. 4a and Supplementary Fig. 11a-c). At such mantle depths, Rcc values are weakly dependent on the effect of grain growth by Ostwald ripening, except if the crystallization zone extends from the surface to deeper than $1000 \mathrm{~km}$. In this case, the fractional crystallization would be even more likely (Fig. 4 and Supplementary Fig. 10). Altogether, we did a very conservative calculation of Rcc in the present study (in particular for heat flux estimations, see Methods section). Therefore, fractional solidification with sedimentation of bridgmanite grains should occur around $1000 \mathrm{~km}$ depth for any MO composition between chondritic-type and peridotite.

We also investigate the possible sedimentation of ferropericlase (Fp), which is the liquidus phase below $35 \mathrm{GPa}$, at least for the peridotitic composition ${ }^{35}$ (Supplementary Fig. 11c, d). Nevertheless, due to its lower density compared to bridgmanite, Fp yields much smaller Rcc values, especially in absence of significant Ostwald ripening. Thus, Fp tends to remain suspended in the melt.

Implications for the state of the Earth's mantle. The sedimentation of bridgmanite grains implies the formation of a bridgmanite-enriched layer at depths around $\sim 1000 \mathrm{~km}$. It also implies an enrichment of a shallow MO toward the peridotitic composition, with a higher $\mathrm{MgO}$ content compared to the primitive chondritic-type mantle. Such chemical fractionation remained only partial, however, as evidenced by the available geochemical constraints ${ }^{36,37}$. Such an early bridgmanite-enriched layer may have survived until present, despite mantle convection, as suggested recently based on geodynamical simulations ${ }^{38}$. Within this assumption, the bridgmanite-enriched layer could cause the viscosity increase reported at mantle depths between 660 and $1500 \mathrm{~km}^{39}$, which appears to impede the dynamic flow in this mantle region ${ }^{40}$.

In a shallow MO, the Rcc values present a major increase above unity when the controlling mechanism for grain size switches from nucleation to grain growth. It corresponds to a major increase of grain size due to Ostwald ripening, favoring fractional crystallization. This effect is more pronounced when the crystallization zone is thick when approaching the Earth surface. The solidification of the upper mantle with fractional solidification of garnets and olivine could have triggered the formation of a protocrust at the surface of the Earth.

\section{Methods}

Experiments at high pressures and high temperatures. Melt viscosities were measured by in-situ falling sphere method in a Kawai-type multi-anvil apparatuses installed at synchrotron-based BL04B1 (SPring-8) and Psiché (SOLEIL) beamlines. We used cubic WC anvils with $26 \mathrm{~mm}$ edge and $4 \mathrm{~mm}$ truncation edge 

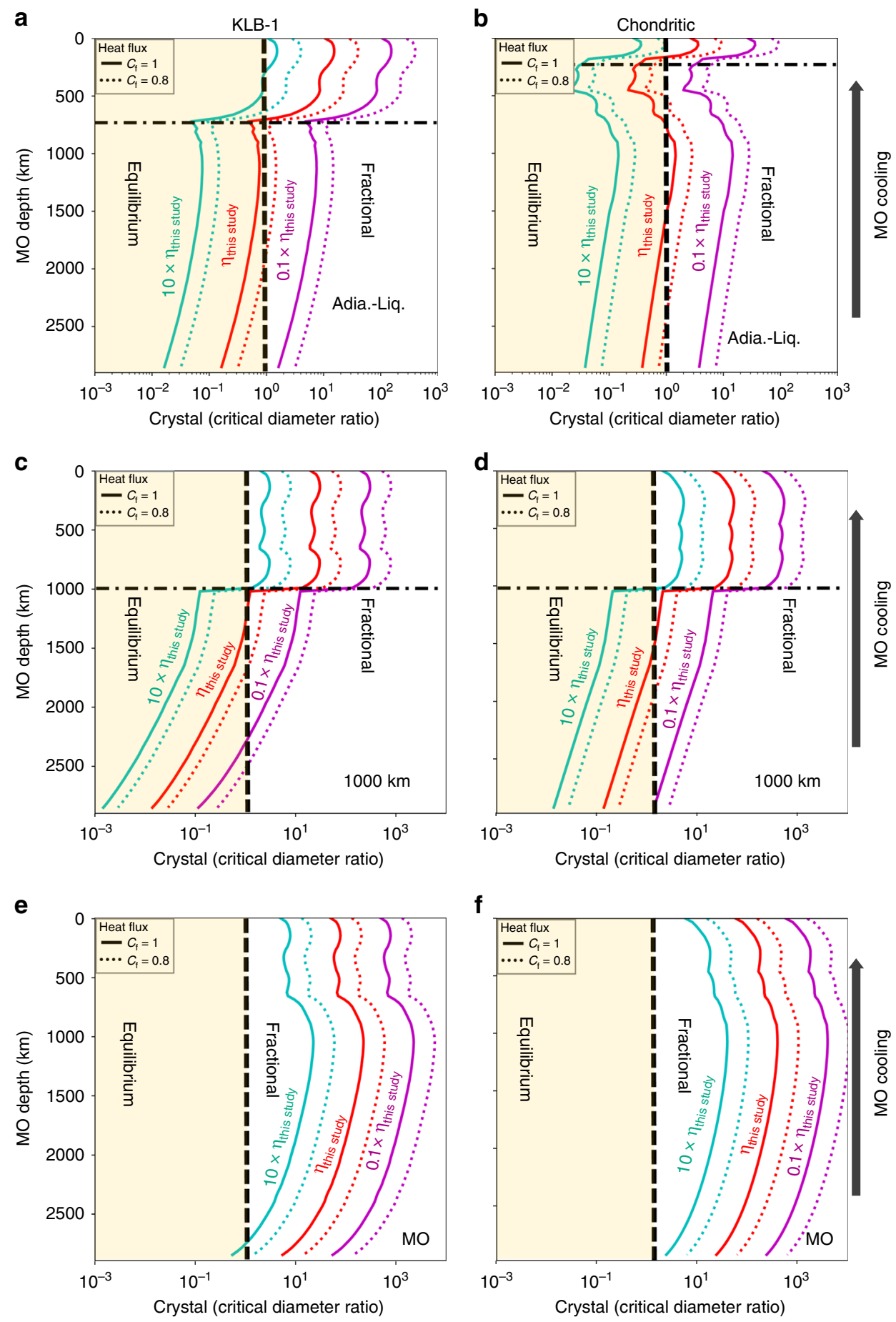

Fig. 4 Crystal/critical diameter ratio as a function of magma ocean depth. Rcc parameter calculated for KLB-1 MO (a, c, e) and chondritic-type MO (b, d, f) using bridgmanite as solid phase and a solid-melt Fe partition coefficient of 0.6. We considered MO viscosities of 10 (green), 1 (red), and 0.1 (blue) times the $\mathrm{MO}$ viscosity determined in this study. Solid or dotted profiles correspond to no blanketing atmosphere $(C f=1)$ or an atmosphere reducing the effective surface temperature by $20 \%(C f=0.8$, see Eq. (16)), respectively. Zones colored in yellow (Rcc lower than 1$)$ or white (Rcc higher than 1$)$ indicate $\mathrm{MO}$ expected to solidify at chemical equilibrium or through fractional solidification with sedimentation of bridgmanite, respectively. The horizontal black dashed-dotted line marks the MO-bottom depth when crystallization starts at the surface of the MO. Upper, middle and lower frames consider a crystallization zone that extends from the $\mathrm{MO}$ bottom to $(\mathbf{a}, \mathbf{b})$ the intersection of adiabatic and liquidus profiles (Adia.-Liq.; see situation (3) in the main text), (c, d) $1000 \mathrm{~km}$ above MO bottom, (e, f) MO surface, respectively.

length to generate pressures up to $\sim 30 \mathrm{GPa}$, corresponding to $\sim 800 \mathrm{~km}$ depths in the Earth's mantle. Pressure medium was $\mathrm{Cr}_{2} \mathrm{O}_{3}$-doped $\mathrm{MgO}$ octahedron of 10 - $\mathrm{mm}$ edge length with edges and vertexes truncated (Supplementary Fig. 1a) The polycrystalline sample was loaded in a graphite capsule. Thermocouple $\left(\mathrm{W}_{97} \mathrm{Re}_{3}-\mathrm{W}_{75} \mathrm{Re}_{25}\right)$ was placed below the graphite capsule. We used $\mathrm{MgO}$ mixed with $10 \mathrm{wt} \%$ diamond (with $\sim 1 \mu \mathrm{m}$ grain size) as internal pressure marker, based on the $P-V$ - $T$ equation of state $(\mathrm{EoS})$ of $\mathrm{MgO}^{41}$. The role of the diamond powder is to prevent the $\mathrm{MgO}$ grain growth. To determine accurate sample pressure, we used an $\mathrm{MgO}$ volume recorded as close as possible from the thermocouple. Pressure uncertainty is estimated to be less than $1 \mathrm{GPa}$, including the propagation of uncertainties on determination of $\mathrm{MgO}$ volume, temperature (see below) and the EoS itself. 
To ensure laminar flow during the fall of the Re sphere in the low-viscosity silicate melt, a Re sphere of $\sim 70 \mu \mathrm{m}$ diameter was placed near the top and at the center of the sample. The spheres were prepared from stripes of $25 \mu \mathrm{m}$ thick Re foil by applying a flash current at $100 \mathrm{~V}$. The Re stripes were immerged in liquid nitrogen to prevent oxidization and enhance the quenching rate. The sphere diameters were measured using a field emission scanning electron microscope with an accuracy better than $\pm 2 \mu \mathrm{m}$. The recovered samples were confirmed to be free from any chemical reaction between the Re spheres and the silicate melt (Supplementary Fig. 1c).

As heater, we used graphite or boron doped diamond (BDD) at pressures lower or higher than $8 \mathrm{GPa}$, respectively. The $\mathrm{BDD}$ heater can generate temperature as high as $\sim 4000 \mathrm{~K}$ with highly X-ray transparency, which is ideal to perform in-situ falling sphere viscometry at high pressures in multi-anvil apparatus ${ }^{13}$. The accurate determination of the falling-sphere terminal velocity in low-viscosity melts requires the use of ultra-fast camera (1000 fps) coupled with synchrotron X-ray radiography ${ }^{11,12}$

Experimental runs were typically performed as follow: Compression to the target pressure at $300 \mathrm{~K}$, progressive heating to 1273 or $1773 \mathrm{~K}$ (depending on the sample pressure) to determine the power-temperature relation and record the relative positions of the sample and the pressure marker, before we conducted a fast heating (2-4s) up to the maximum target temperature. The target temperature was set a couple $100 \mathrm{~K}$ above the liquidus temperature (from ref. ${ }^{42}$ and references therein for Fo and En and from ref. ${ }^{43}$ and ref. ${ }^{44}$ for Di below and above $17 \mathrm{GPa}$, respectively). Because the thermocouple usually broke during the fast heating ramp, the ramp was monitored based on the power-temperature relation determined previously (see below our simulations of the sample behavior during the fast heating ramp). This procedure yields a temperature uncertainty of $\sim 30 \mathrm{~K}$, or $\sim 150 \mathrm{~K}$, with, or without, a thermocouple reading, respectively. Then, after we observed the sphere falling, we kept the power constant and measured the sample pressure again.

Temperature gradients. To estimate temperature gradients, we recorded diffraction patterns at different positions in the $\mathrm{MgO}$ pressure marker (positions noted P1, P2, and P3 in Supplementary Fig. 1d). Under the assumption of a negligible pressure gradient inside heater, the difference in $\mathrm{MgO}$ volumes can be attributed to a temperature difference. At a thermocouple temperature of $1273 \mathrm{~K}$, the resulted temperature difference is less than $60 \mathrm{~K}$ between the thermocouple and center of capsule, and less than $10 \mathrm{~K}$ between the center and the top of capsule.

\section{Simulations of the sample behavior during the final heating procedure. To} prevent a chaotic fall of the Re-sphere in a partially molten sample, the final heating step consisted in a ramp of fast heating. For a liquidus temperature expected $2500 \mathrm{~K}$, for example, we typical set a heating ramp from 1773 to $3000 \mathrm{~K}$ within a duration of $2 \mathrm{~s}$ (i.e. $\sim 600 \mathrm{~K} / \mathrm{s}$ ). To model the sample behavior during this ramp, we conducted finite element simulation using the $\mathrm{COMSOL}^{\mathrm{mm}}$ software. To simplify the sample geometry without losing the essence of the critical part inside the heater, the octahedral shape of the pressure medium was modeled as a cylinder. The sample thermal conductivity was assumed to be 50 and $2.5 \mathrm{~W} /(\mathrm{mK})$ before and after melting, respectively.

Our calculations show that the effect of the latent heat of fusion turned out to be negligible. The temperature gradients in the capsule are within $\sim 20 \mathrm{~K}$, in good agreement with our estimates based on the $\mathrm{MgO}$ equation of state. The measurement of the falling sphere velocity is performed at an "overshoot temperature" above the liquidus, which can be estimated from the time consumed to reach the terminal velocity. For the sample MA24, the terminal velocity is achieved in less than $\sim 0.3 \mathrm{~s}$ after the onset of the sphere fall. With a heating ramp of $600 \mathrm{~K} / \mathrm{s}$, this implies that the terminal velocity is achieved at about $180 \mathrm{~K}$ above the liquidus temperature, a temperature gap similar to the uncertainty in the temperature determination using the relation between the furnace-power and the sample temperature

Viscosity calculation. The falling sphere velocity was determined based on the recording of high quality images using the fast camera (1000 fps) installed at the synchrotron facilities. The falling speed first increases before it reaches a constant (terminal) velocity (Fig. 1). The distance interval where terminal velocity was reached, was determined through the velocity-time diagram (Fig. 1c). The terminal velocity $\left(v_{s}\right)$ corresponds to the state where viscous forces are equilibrated with the gravitational force. The Reynold numbers of all our experiments $(0.01-0.1)$ are far smaller than 1 , which is in the laminar flow regime. Therefore, the terminal velocity yields the melt viscosity $(\eta)$, based on the Stokes law:

$$
\begin{gathered}
\eta=\frac{2 g r_{s}^{2}\left(\rho_{\mathrm{s}}-\rho_{\mathrm{m}}\right) W}{9 v_{\mathrm{s}} E} \\
W=1-2.104\left(\frac{r_{\mathrm{s}}}{r_{\mathrm{c}}}\right)+2.09\left(\frac{r_{\mathrm{s}}}{r_{\mathrm{c}}}\right)^{3}-0.95\left(\frac{r_{\mathrm{s}}}{r_{\mathrm{c}}}\right)^{5} \\
E=1+3.3\left(\frac{r_{\mathrm{s}}}{h_{\mathrm{c}}}\right)
\end{gathered}
$$

where $r_{\mathrm{s}}, \rho_{\mathrm{s}}, \rho_{\mathrm{m}}$, and $g$ correspond to sphere radius, sphere density, melt density, and acceleration due to gravity, respectively. $W$ and $E$ are correction factors accounting for the presence of walls and end in a sample container of radius $r_{\mathrm{c}}$ and height $h_{\mathrm{c}}{ }^{45}$. The radius and the density of the Re spheres were corrected for the effect of pressure using the EoS of Re ${ }^{46}$. The density of Fo, En, and Di melts were calculated based on the available $\operatorname{EOS}^{47-49}$

Error analysis and reproducibility. We conducted Monte Carlo simulations to evaluate the propagation of experimental uncertainties on pressure, temperature, terminal velocity and sphere size. Gaussian distribution of experimental uncertainties was assumed. The sampling number was 10,000. The results for Run S3219 (En, 24.1 GPa, $2836 \mathrm{~K}$ ) are presented as an example (Supplementary Fig. 3). Even though the relative uncertainties of pressure and temperature are larger $(\sim 3.6 \%)$ than those of terminal velocity (0.5\%), their contribution to the final viscosity is 1 order of magnitude smaller. This is because the density contrast between sphere and melts is not sensitive to pressure and temperature. The main source of uncertainty for the final determination of the melt viscosity is caused by the uncertainty of $2.9 \%$ on the sphere diameter, which is elevated to a quadratic power in the expression of viscosity. The total error on viscosity is within $6 \%$, with an almost Gaussian distribution (Supplementary Table 1).

Reproducibility of our measurements was checked by performing repeated experiments at similar pressures, temperatures and with different sphere sizes (such as run S3170 and S3171, S3172 and S3175, S3257 and S3260 in Supplementary Table 1). The difference between repeated experiments remains within $6 \%$, which is consistent with the estimated viscosity error.

Viscosity of peridotite composition in MO. Bottinga and Weill (1972) ${ }^{50}$ proposed that the logarithm viscosity of a multi-components melt at super-liquidus conditions can be satisfactorily expressed as a linear function of the logarithm viscosity of the end-member compositions over a restricted composition interval (for example $\mathrm{SiO}_{2}$ mole content from $30-50 \%$ ). This model is supported by the Adam-Gibbs theory, because viscosity can be expressed as a function of the configuration entropy $\left(S^{\text {conf }}\right)^{26}$ :

$$
\begin{gathered}
\eta=A_{\mathrm{e}} \exp \left(\frac{B_{\mathrm{e}}}{\mathrm{TS}^{\mathrm{conf}}}\right) \\
S^{\mathrm{conf}}(\mathrm{T})=\sum x_{\mathrm{i}} S_{\mathrm{i}}^{\mathrm{conf}}(T)+S_{\text {mix }} \\
S_{\text {mix }}=-\mathrm{nR} \sum x_{\mathrm{i}} \ln x_{\mathrm{i}}
\end{gathered}
$$

where $n$ is the number of entities exchanged per formula unit. When temperature is near liquidus or higher, $S_{\text {mix }}$ is very small and negligible. Therefore, we can use linear combination of logarithmic viscosity. This model was experimentally confirmed for the $\mathrm{Ca}-\mathrm{Mg}$ exchange in molten garnets and pyroxenes ${ }^{51}$ and for $\mathrm{Na}-\mathrm{K}$ exchange in alkali-silicates ${ }^{52}$. In our case, we model the viscosity of mantle melts with KLB-1 or chondritic-type compositions (Supplementary Table 4) based on four end-members, Fo, En, Di, and An:

$$
\ln \left(\eta_{\text {mantle }}\right)=f_{\mathrm{Fo}} \times \ln \left(\eta_{\mathrm{Fo}}\right)+f_{\mathrm{En}} \times \ln \left(\eta_{\mathrm{En}}\right)+f_{\mathrm{Di}} \times \ln \left(\eta_{\mathrm{Di}}\right)+f_{\mathrm{An}} \times \ln \left(\eta_{\mathrm{An}}\right)
$$

where $f i$ are the molar contents of each endmember. Viscosity of Fo, En, Di melts are provided from the present work and viscosity of An was reported from first principle calculation ${ }^{27}$. We chose viscosity function of Fo for both Fo and Fa components. Because Fa component represents less than $8 \%$ of the KLB-1 and Chondritic composition and, in addition, viscosities of $\mathrm{Fa}$ and Fo converge to the same value (the difference is within $\sim 10 \%$ ) with increasing pressure (Supplementary Fig. 6). The total error caused by ignoring the Fa component is less than $0.8 \%$

Temperature at the bottom of a MO. In this work, we defined the bottom of the $\mathrm{MO}$ as the mantle depth where the rheological transition first occurs, at a crystal fraction of $60 \%$. The temperature at this depth $\left(T_{\text {Rheo }}\right)$ is at an intermediate temperature between the solidus $\left(T_{\text {sol }}\right)$ and the liquidus $\left(T_{\mathrm{Liq}}\right)$. By lack of knowledge, we assume a linear evolution of the degree of partial melting between $T_{\mathrm{sol}}$ and $T_{\text {Liq }}$ (as in ref. ${ }^{53}$ ). Therefore, $T_{\text {Rheo }}$ equals $0.4 \times T_{\text {Liq }}+0.6 \times T_{\text {sol }}$.

For the peridotitic mantle composition, we used $T_{\text {sol }}$ and $T_{\text {Liq }}$ profiles from ref. ${ }^{54}$ and ref. ${ }^{55}$, respectively, while for a chondritic-type mantle, we considered the $T_{\text {sol }}$ and $T_{\text {Liq }}$ from ref. ${ }^{56}$ at pressures $>8 \mathrm{GPa}$ and from ref. ${ }^{57}$ at pressures $<=$ $8 \mathrm{GPa}$.

The critical grain diameter for sedimentation in a convecting MO. The critical diameter is the maximum size of crystal that the MO convection can suspend. In this case, the viscous dissipation equals the total heat loss rate from the $\mathrm{MO}^{5}$

$$
W=\frac{\alpha g L F A}{c_{\mathrm{p}}}
$$

where $L, A$ are the MO depth and surface, respectively; $F$ the heat flux through the $\mathrm{MO} ; \alpha$ the averaged thermal expansion coefficient of MO; $W$ the viscous 
dissipation energy.

$$
W=v_{\mathrm{s}} g \int_{L_{\mathrm{CZT}}}^{L} \Phi \Delta \rho \mathrm{d} V
$$

$v_{\mathrm{s}}$ is the relative velocity between crystal and melt, $g$ gravity acceleration, $\Delta \rho$ the averaged density contrast between melt and crystal, $V$ the volume of crystallization zone, $\Phi$ the crystal fraction, $L_{\mathrm{C} Z \mathrm{~T}}$ is the depth of top surface of crystallization zone.

Assuming linearly increase of $\Phi$ with depth from 0 at top of crystallization zone to $\sim 0.6$ at the viscous transition. At a given depth (D), $\Phi$ can be expressed as:

$d V$ can be expressed as:

$$
\Phi=\frac{0.6\left(D-L_{\mathrm{CZT}}\right)}{L-L_{\mathrm{CZT}}}
$$

$$
d V=4 \pi(R-D)^{2} d D
$$

where $R$ is the Earth's diameter

Combining Eqs. (11-14), we obtain:

$$
v_{\mathrm{s}} g \int_{L_{\mathrm{CZT}}}^{L} \frac{0.6\left(D-L_{\mathrm{CZT}}\right) \Delta \rho 4 \pi(R-D)^{2}}{L-L_{\mathrm{CZT}}} d D=\frac{\alpha g L F A}{c_{p}}
$$

In the early stages of the $\mathrm{MO}$ crystallization, the surface temperature of $\mathrm{MO}$ $\left(T_{\text {sur }}\right)$ is expected to be more than $2000 \mathrm{~K}$, producing an atmosphere made of silicate rock vapor ${ }^{58}$. In such conditions, the heat flux at the MO surface is estimated by:

$$
F=\sigma_{\mathrm{SB}}\left(C_{\mathrm{f}} T_{\text {sur }}\right)^{4}
$$

where $\sigma_{\mathrm{SB}}$ is the Stefan-Boltzmann constant and $C_{f}$ the ratio between the effective surface temperature (the temperature that would produce a given heat flux $F$ ) and $T_{\text {sur. }}$. For a moderately opaque atmosphere with $C_{f}=0.75$, the heat flux is $\sim 3$ times lower than that for $C_{f}=1 . T_{\text {sur }}$ is related to the potential temperature $\left(T_{\text {poten }}\right)$ of MO through the scaling law. When $T_{\text {poten }}$ is $2000 \mathrm{~K}, T_{\text {sur }}$ is $\sim 1800 \mathrm{~K}$ and $1400 \mathrm{~K}$ for hard and soft turbulent convection, respectively ${ }^{5}$. Here, we assume the $T_{\text {sur }}$ equals $T_{\text {poten }}$. Therefore, $T_{\text {sur }}$ is overestimated by 1.1 to 1.4 times.

Combining Eqs. (11), (12) and (16), we obtain:

$$
v_{s}=\frac{\alpha L A \sigma_{\mathrm{SB}}\left(C_{f} T_{\text {sur }}\right)^{4}}{c_{\mathrm{p}} \Phi \Delta \rho V}
$$

The overestimation of $T_{\mathrm{sur}}$ causes an overestimation of $v_{\mathrm{s}}$ by $\sim 1.4$ to 4 times.

When crystals are suspended in the melt, the viscous drag (right part of Eq. 14) balances the buoyancy force (left part of Eq. 14). Assuming a crystal with a sphere shape, we obtain:

$$
\frac{4 \pi \Delta \rho g\left(\frac{d}{2}\right)^{3}}{3}=\frac{C_{d} \rho_{l}\left(\frac{v_{s}}{f_{s}}\right)^{2} \pi\left(\frac{d}{2}\right)^{2}}{2}
$$

and thus,

$$
d c=\frac{3 C_{d} \rho_{l}\left(\frac{v_{s}}{f_{\Phi}}\right)^{2}}{4 \Delta \rho g}
$$

where $\mathrm{d} c$ is the critical crystal diameter, $\rho_{l}$ the average density of melt in the crystallization zone, $C_{\mathrm{d}}$ the drag coefficient and $f_{\Phi}$ the hindered settling function. Because the crystal fraction in the crystallization varies from 0 to 0.6 as a function of mantle depth and time, we consider an average crystal fraction of $30 \%$, which corresponds to a $f_{\Phi}$ value of $0.15^{59}$. The drag coefficient depends on the shape of particle and the Reynolds number

$$
\operatorname{Re}=\frac{\rho_{l}\left(\frac{v_{s}}{f_{\Phi}}\right) d c}{\eta_{l}}
$$

Where $\eta_{l}$ is the averaged viscosity in the crystallization zone.

For a spherical shape, $C_{\mathrm{d}}$ can be expressed as ${ }^{60}$ :

$$
C_{\mathrm{d}}=\frac{24}{\mathrm{Re}}+\frac{2.6\left(\frac{\mathrm{Re}}{5.0}\right)}{1+\left(\frac{\mathrm{Re}}{5.0}\right)^{1.52}}+\frac{0.411\left(\frac{\mathrm{Re}}{2.6 \times 10^{5}}\right)^{-7.94}}{1+\left(\frac{\mathrm{Re}}{2.6 \times 10^{5}}\right)^{-8.00}}+\frac{0.25\left(\frac{\mathrm{Re}}{10^{6}}\right)}{1+\left(\frac{\mathrm{Re}}{10^{6}}\right)}
$$

Combining Eqs. (19-21), we can obtain $d c$ numerically. The Reynolds number in $\mathrm{MO}$ is less than 20 when grain size in MO equals critical size (Supplementary Fig. 7e, f). Thus, $C_{\mathrm{d}}$ is larger than 1 . Because we overestimate the heat flux by $\sim 1.4$ to 4 times, the calculated value of $d c$ is at least overestimated by $\sim 2$ or 14 times.

The diameter of crystals in the MO. The controlling mechanism for crystal size in the MO is nucleation or grain growth before or after, respectively, a fully-molten layer disappears at the shallow mantle depths. Before a fully-molten layer disappears at the shallow mantle depths, crystals nucleate, grow and dissolve on the course of their vertical movement in the convecting MO. The nucleation size can be estimated using the following equation ${ }^{5}$

$$
d_{\text {nucl }} \approx 0.001\left(\frac{\sigma_{\text {app }}}{0.02 \mathrm{~J} \mathrm{~m}^{-2}}\right)\left(\frac{D}{10^{-9} \mathrm{~m}^{2} \mathrm{~s}^{-1}}\right)^{1 / 2}\left(\frac{\mu_{0}}{10 \mathrm{~m} \mathrm{~s}^{-1}}\right)^{-1 / 2}
$$

where $\sigma_{\mathrm{app}}$ is the apparent surface energy, $D$ the diffusion coefficient in the melt and $\mu_{0}$ the convection velocity. $\mu_{0}$ is correlated to the heat flux ${ }^{5}$.

$$
\mu_{0}=14\left(\frac{\alpha g F}{\rho c_{p} \Omega}\right)^{1 / 2}
$$

where $\rho$ is the averaged melt density of $\mathrm{MO}$ and $\Omega$ the angular velocity. On the other hand, the coefficient $D$ in Eq. (22) can be related to the melt viscosity using the Eyring equation ${ }^{61}$ :

$$
D=\frac{k T_{z}}{\lambda \eta_{l}}
$$

where $k$ is the Boltzmann constant, $T_{z}$ the average temperature in the crystallization zone and $\lambda$ the ionic translation distance, for which we used the diameter of oxygen anion $(2.8 \AA)$. Finally, using parameters typical of the MO (Supplementary Table 5), we obtain:

$$
d_{\text {nucl }} \approx 0.001183\left(\frac{D}{10^{-9} \mathrm{~m}^{2} \mathrm{~s}^{-1}}\right)^{1 / 2}\left(\frac{\alpha g F}{\rho c_{p} \Omega}\right)^{-1 / 4}
$$

During the residence time of crystals in the partially molten layer of $\sim 10^{6} \mathrm{~s}$ (roughly one week $)^{5}$, crystal growth $\left(d_{\mathrm{Os}}\right)$ due to Ostwald ripening can be estimated as ${ }^{5}$

$$
d_{\mathrm{Os}} \approx 0.001\left(\left(\frac{D}{10^{-9} \mathrm{~m}^{2} \mathrm{~s}^{-1}}\right)^{1 / 3}\left(\frac{\mu_{0}}{10 \mathrm{~m} \mathrm{~s}^{-1}}\right)^{-1 / 3}\right.
$$

This is similar to nucleation size and, thus, the crystal size is not increased substantially by Ostwald ripening. Therefore, the crystal size is mainly controlled by its nucleation size, when the crystallization zone is covered by a fully-molten layer. In such conditions, we can ignore grain growth and Eq. (25) provides a lower limit for the crystal size in the crystallization zone.

$$
d_{\text {crystal }}=d_{\text {nucl }}
$$

When the MO temperature is below the liquidus profile at all depths, some crystals will survive and grow until final settling at the MO bottom. Let's assume $\mathrm{d} t$ is the time needed to freeze a small depth $\mathrm{d} L$ of the $\mathrm{MO}$ after temperature drops by $d T$ in the $\mathrm{MO}$ and $d T_{\text {sur }}$ at the Earth's surface. If we ignore the energy released due to (i) crystallization and (ii) mantle cooling below the MO-bottom $(L)$, we obtain

$$
\frac{d t}{d L}=\frac{M_{\mathrm{MO}} c_{\mathrm{p}} d T}{F A}
$$

$M_{\mathrm{MO}}$ is the total mass of a $\mathrm{MO}$ extending up to a depth $L$. According to the adiabatic profile in the MO (Fig. $3 \mathrm{c}, \mathrm{d}$ ), $d T>d T_{\text {sur. }}$. We obtain:

$$
\frac{\mathrm{d} t}{\mathrm{~d} L}>\frac{M_{\mathrm{MO}} c_{\mathrm{p}} \mathrm{d} T_{\text {sur }}}{F A}
$$

Let's assume $L_{\mathrm{m}}$ the MO depth when, upon cooling, its temperature becomes lower than the mantle liquidus at the surface. The residence time of crystals in a MO with depth $L\left(L<L_{\mathrm{md}}\right)$ equals the time for the bottom of the MO to solidified from $L_{\mathrm{md}}$ to $L$ :

$$
t_{\text {residence }}>\int_{L}^{L_{\mathrm{md}}} \frac{M_{\mathrm{MO}} c_{\mathrm{p}} \mathrm{d} T_{\text {sur }}}{F A} \mathrm{~d} L
$$

The average freezing time, calculated using Eq. (30) is $~ 10$ years per kilometer Under such cooling rate, crystals can grow substantially after their formation by Ostwald ripening. Under a diffusion-controlled mechanism, crystal size is proportional to $t_{\text {residual }} 1 / 35,62$.

$$
d_{\text {crystal }} \approx\left(\frac{t_{\text {residence }}}{10^{6}}\right)^{1 / 3} d_{\text {nucl }}
$$

The lower limit of crystal size can be expressed as:

$$
d_{\text {crystal }}=\left(\frac{\int_{L}^{L_{\text {md }} \frac{M_{\mathrm{MO}} c_{\mathrm{p}} \mathrm{d} T_{\text {surface }}}{F A} \mathrm{~d} L}}{10^{6}}\right)^{1 / 3} d_{\text {nucl }}
$$

Crystal/critical diameter ratio in a crystallizing MO. We can now define the ratio of crystal/critical grain diameter (Rcc):

$$
\mathrm{Rcc}=\frac{d_{\text {crystal }}}{d_{\mathrm{c}}}
$$

Rcc values higher, or lower, than unity correspond to the grain sedimentation at the bottom of the MO (fractional solidification), or grain suspension in the convective MO (equilibrium solidification), respectively. Since our model overestimates critical size $\left(d_{\mathrm{c}}\right)$ by $\sim 2$ or 14 times and uses a lower limit of crystal size $\left(d_{\text {crystal }}\right)$, it also underestimates the Rcc value and favors equilibrium solidification.

Density of melt and crystal in MO. On the course of $\mathrm{MO}$ cooling, we considered the possible crystallization of bridgmanite $\left(\left(\mathrm{Mg}_{1-x} \mathrm{Fe}_{x}\right) \mathrm{SiO}_{3}\right)$ or ferropericlase $\left(\mathrm{Mg}_{1-x} \mathrm{Fe}_{\mathrm{x}}\right) \mathrm{O}$ at pressures above $23 \mathrm{GPa}$, garnet $\left(\left(\mathrm{En}_{80} \mathrm{Py}_{20}\right)_{1-x} \mathrm{Al}_{x}\right)$ between 
15 and $23 \mathrm{GPa}$, and olivine $\left(\left(\mathrm{Mg}_{1-x} \mathrm{Fe}_{x}\right)_{2} \mathrm{SiO}_{4}\right)$ below $15 \mathrm{GPa}$. As our results show that crystal fractionation remains limited to some mantle regions, we assume a constant melt composition on the course of the MO solidification. Density of the MO melt was calculated from endmember melt compositions using the ideal mixing model ${ }^{63}$. Iron content in crystals were calculated based on the melt composition and crystal-melt partition coefficients. We considered partition coefficients varying from 0.2 to 0.6 , due to remaining experimental uncertainties (see ref. ${ }^{3}$ and references therein). To calculate density of bridgmanite, ferropericlase, majorite and olivine, we used an ideal lattice mixing model ${ }^{64}$ between end-member compositions with the following EoS: bridgmanite $\left(\left(\mathrm{Mg}_{1-x} \mathrm{Fe}_{\mathrm{x}}\right) \mathrm{SiO}_{3}\right) ; 64\left(\mathrm{Mg}_{1-x}\right.$ $\left.\mathrm{Fe}_{\mathrm{x}}\right) \mathrm{O}$ as a solid solution of $\mathrm{MgO}^{37}$ and $\left.\mathrm{FeO} ; 65 \mathrm{En}_{80} \mathrm{Py}_{20}\right)_{1-x} \mathrm{Al}_{x}$ as a solid solution of $\mathrm{En}_{80} \mathrm{Py}_{20}{ }^{66}$ and Almandine; $\left.{ }^{67} \mathrm{Ol}\left(\mathrm{Mg}_{1-x} \mathrm{Fe}_{x}\right)_{2} \mathrm{SiO}_{4}\right)$ as a solid solution of $\left(\mathrm{Mg}_{0.9} \mathrm{Fe}_{0.1}\right)_{2} \mathrm{SiO}_{4}{ }^{68}$ and $\mathrm{Mg}_{2} \mathrm{SiO}_{4}{ }^{69}$.

\section{Data availability}

The authors declare that the majority of the data supporting the findings of this study are available in the paper or supplementary materials. The unpublished data are available from the corresponding author upon request. An example sphere falling videos is available in the supplementary video

\section{Code availability}

The Monte Carlo simulation and finite element simulation were conducted with a commercial software MATLAB ${ }^{\mathrm{si}}$ and $\mathrm{COMSOL}^{\mathrm{m}}{ }^{\mathrm{N}}$, respectively. The images were analysis using public software Fiji, which is an open source image processing package based on ImageJ.

Received: 4 May 2019; Accepted: 10 December 2019; Published online: 28 January 2020

\section{References}

1. Carlson, R. W. et al. How did early earth become our modern world? Annu. Rev. Earth Planet. Sci. 42, 151-178 (2014).

2. Labrosse, S., Hernlund, J. W. \& Coltice, N. A crystallizing dense magma ocean at the base of the Earth's mantle. Nature 450, 866-869 (2007).

3. Williams, C. D. \& Mukhopadhyay, S. Capture of nebular gases during Earth's accretion is preserved in deep-mantle neon. Nature 565, 78 (2019).

4. Touboul, M., Puchtel, I. S. \& Walker, R. J. W-182 evidence for long-term preservation of early mantle differentiation products. Science 335, 1065-1069 (2012).

5. Solomatov, V. S. Fractional versus equilibrium crystallization. Magma oceans and primordial mantle differentiation. Treatise Geophys. 9, 91-120 (2007).

6. Nevins, D., Spera, F. J. \& Ghiorso, M. S. Shear viscosity and diffusion in liquid $\mathrm{MgSiO}_{3}$ : transport properties and implications for terrestrial planet magma oceans. Am. Min. 94, 975-980 (2009).

7. Karki, B. B. \& Stixrude, L. P. Viscosity of $\mathrm{MgSiO}_{3}$ liquid at Earth's mantle conditions: implications for an early magma ocean. Science 328, 740-742 (2010).

8. Ghosh, D. B. \& Karki, B. B. Diffusion and viscosity of $\mathrm{Mg}_{2} \mathrm{SiO}_{4}$ liquid at high pressure from first-principles simulations. Geochim. Cosmochim. Acta 75, 4591-4600 (2011).

9. Verma, A. K. \& Karki, B. B. First-principles study of self-diffusion and viscous flow in diopside $\left(\mathrm{CaMgSi}_{2} \mathrm{O}_{6}\right)$ liquid. Am. Min. 97, 2049-2055 (2012).

10. Reid, J. E. et al. The viscosity of $\mathrm{CaMgSi}_{2} \mathrm{O}_{6}$ liquid at pressures up to $13 \mathrm{GPa}$. Phys. Earth Planet. Inter 139, 45-54 (2003).

11. Spice, H. et al. Viscosity of liquid fayalite up to 9GPa. Geochim. Cosmochim. Acta 148, 219-227 (2015).

12. Cochain, B., Sanloup, C., Leroy, C. \& Kono, Y. Viscosity of mafic magmas at high pressures. Geophys. Res. Lett. 44, 818-826 (2017).

13. Xie, L. et al. Synthesis of boron-doped diamond and its application as a heating material in a multi-anvil high-pressure apparatus. Rev. Sci. Instrum. 88, 093904 (2017).

14. Urbain, G., Bottinga, Y. \& Richet, P. Viscosity of liquid silica, silicates and alumino-silicates. Geochim. Cosmochim. Acta 46, 1061-1072 (1982).

15. Scarfe, C. M. Pressure dependence of the viscosity of silicate melts. Magmatic processes: physicochemical Principles 59-67 (1987).

16. Taniguchi, H. Entropy dependence of viscosity and the glass-transition temperature of melts in the system diopside-anorthite. Contrib. Mineral. Petrol. 109, 295-303 (1992).

17. Reid, J. E. et al. The self-diffusion of silicon and oxygen in diopside $\left(\mathrm{CaMgSi}_{2} \mathrm{O}_{6}\right)$ liquid up to 15GPa. Chem. Geol. 174, 77-86 (2001).

18. Suzuki, A. et al. Viscosity of albite melt at high pressure and high temperature. Phys. Chem. Miner. 29, 159-165 (2002).

19. Karki, B. B. et al. Simulation of silicate melts under pressure, In: Magmas Under Pressure 419-453 (Elsevier, 2018).
20. Sakamaki, T. et al. Ponded melt at the boundary between the lithosphere and asthenosphere. Nat. Geosci. 6, 1041 (2013).

21. Wang, Y. et al. Atomistic insight into viscosity and density of silicate melts under pressure. Nat. Commun. 5, 3241 (2014)

22. Noritake, F. \& Kawamura, K. Structural transformations in sodium silicate liquids under pressure: a molecular dynamics study. J. Non-Cryst. Solids 447, 141-149 (2016).

23. Bauchy, M., Guillot, B., Micoulaut, K. \& Sator, N. Viscosity and viscosity anomalies of model silicates and magmas: a numerical investigation. Chem. Geol. 346, 47-56 (2013).

24. Xue, X., Kanzaki, M., Trønnes, R. G. \& Stebbins, J. F. Silicon coordination and speciation changes in a silicate liquid at high pressures. Science 245, 962-964 (1989).

25. S. Sanloup, C. Density of magmas at depth. Chem. Geol. 429, 51-59 (2016).

26. Richet, P. \& Bottinga, Y. Composition dependence of the viscosity. Rheology and configurational entropy of silicate melts. Rev. Miner. Geochem. 32, 81-82 (1995).

27. Karki, B. B., Bohara, B. \& Stixrude, L. First-principles study of diffusion and viscosity of anorthite $\left(\mathrm{CaAl}_{2} \mathrm{Si}_{2} \mathrm{O}_{8}\right)$ liquid at high pressure. Am. Min. 96, 744-775 (2011)

28. Persikov, E. S. et al. The effect of volatiles on the properties of magmatic melts. Eur. J. Miner. 2, 621-642 (1997).

29. Whittington, A. et al. Water and the viscosity of depolymerized aluminosilicate melts. Geochim. Cosmochim. Acta 64, 3725-3736 (2000).

30. Liebske, C. et al. Viscosity of peridotite liquid up to $13 \mathrm{GPa}$ : implications for magma ocean viscosities. Earth Planet. Sci. Lett. 240, 589-604 (2005).

31. Lejeune, A. M. \& Richet, P. Rheology of crystal-bearing silicate melts: an experimental study at high viscosities. J. Geophys. Res. 100(B3), 4215-4229 (1995).

32. Andrault, D. et al. Solid-liquid iron partitioning in Earth's deep mantle. Nature 487, 354 (2012).

33. Miller, G. H., Stolper, E. M. \& Ahrens, T. J. The equation of state of a molten komatiite: 2. Application to komatiite petrogenesis and the Hadean mantle. J. Geophys. Res. 96(B7), 11849-11864 (1991).

34. Cuk, M. \& Stewart, S. T. Making the Moon from a fast-spinning Earth: a giant impact followed by resonant despinning. Science 338, 1047-1052 (2012).

35. Ito, E., Kubo, A., Katsura, T. \& Walter, M. J. Melting experiments of mantle materials under lower mantle conditions with implications for magma ocean differentiation. Phys. Earth Planet. Inter 143, 397-406 (2004).

36. Walter, M. J., Nakamura, E., Trønnes, R. G. \& Frost, D. J. Experimental constraints on crystallization differentiation in a deep magma ocean. Geochim. Cosmochim. Acta 68, 4267-4284 (2004).

37. McDonough, W. F. \& Sun, S. S. The composition of the Earth. Chem. Geol. 120, 223-253 (1995).

38. Ballmer, M. D. et al. Persistence of strong silica-enriched domains in the Earth's lower mantle. Nat. Geosci. 10, 236 (2017).

39. Rudolph, M. L., Lekić, V. \& Lithgow-Bertelloni, C. Viscosity jump in Earth's mid-mantle. Science 350, 1349-1352 (2015).

40. Fukao, Y. \& Obayashi, M. Subducted slabs stagnant above, penetrating through, and trapped below the $660 \mathrm{~km}$ discontinuity. J. Geophys. Res. 118, 5920-5938 (2013).

41. Tange, Y., Nishihara, Y., \& Tsuchiya, T. Unified analyses for P-V-T equation of state of MgO: a solution for pressure-scale problems in high P-T experiments. J. Geophys. Res. 114, B03208 (2009).

42. Presnall, D. C. Phase diagrams of Earth-forming minerals. Miner. Phys. Cryst 2, 248-268 (1995)

43. Gasparik, T. Melting experiments on the enstatite-diopside join at 70-224 kbar, including the melting of diopside. Contrib. Miner. Petrol. 124, 139-153 (1996).

44. Shen, G. \& Lazor, P. Measurement of melting temperatures of some minerals under lower mantle pressures. J. Geophys. Res. 100(B9), 17699-17713 (1995)

45. Faxén, H. Der Widerstand gegen die Bewegung einer starren Kugel in einer zähen Flüssigkeit, die zwischen zwei parallelen ebenen Wänden eingeschlossen ist. Ann. der Phys. 373, 89-119 (1922).

46. Zha, C. S., Bassett, W. A. \& Shim, S. H. Rhenium, an in situ pressure calibrant for internally heated diamond anvil cells. Rev. Sci. Instrum. 75, 2409-2418 (2004).

47. de Koker, N. P., Stixrude, L. \& Karki, B. B. Thermodynamics, structure dynamics, and freezing of $\mathrm{Mg}_{2} \mathrm{SiO}_{4}$ liquid at high pressure. Geochim. Cosmochim. Acta 72, 1427-1441 (2008).

48. Petitgirard, S. et al. Fate of $\mathrm{MgSiO}_{3}$ melts at core-mantle boundary conditions. Proc. Natl Acad. Sci. USA 112, 14186-14190 (2015).

49. Rigden, S. M., Ahrens, T. J. \& Stolper, E. M. High-pressure equation of state of molten anorthite and diopside. J. Geophys. Res. 94(B7), 9508-9522 (1989)

50. Bottinga, Y. \& Weill, D. F. The viscosity of magmatic silicate liquids; a model calculation. Am. J. Sci. 272, 438-475 (1972)

51. Neuville, D. R. \& Richet, P. Viscosity and mixing in molten (Ca, Mg) pyroxenes and garnets. Geochim. Cosmochim. Acta 55, 1011-1019 (1991). 
52. Richet, P. Viscosity and configurational entropy of silicate melts. Geochim. Cosmochim. Acta 48, 471-483 (1984).

53. Abe, Y. Thermal and chemical evolution of the terrestrial magma ocean. Phys. Earth Planet. Int. 100, 27-39 (1997).

54. Fiquet, G. et al. Melting of peridotite to 140 gigapascals. Science 329, 1516-1518 (2010).

55. Stixrude, L. et al. Thermodynamics of silicate liquids in the deep Earth. Earth Planet. Sci. Lett. 278, 226-232 (2009).

56. Andrault, D. et al. Solidus and liquidus profiles of chondritic mantle: implication for melting of the Earth across its history. Earth Planet. Sci. Lett. 304, 251-259 (2011).

57. Litasov, K. \& Ohtani, E. Phase relations and melt compositions in CMASpyrolite- $\mathrm{H}_{2} \mathrm{O}$ system up to $25 \mathrm{GPa}$. Phys. Earth Planet. Int. 134, 105-127 (2002).

58. Nakazawa, K., Mizuno, H., Sekiya, M. \& Hayashi, C. Structure of the primordial atmosphere surrounding the early Earth. J. Geomag. Geoelectr. 37, 781-799 (1985).

59. Davis, R. H. \& Acrivos, A. Sedimentation of noncolloidal particles at low Reynolds numbers. Annu. Rev. Fluid Mechan. 17, 91-118 (1985).

60. Morrison, A. Noncreeping flow around a sphere. In: An Introduction to Fluid Mechanics. Vol. 624 (Cambridge University Press, New York, 2013).

61. Eyring, H. Viscosity, plasticity, and diffusion as examples of absolute reaction rates. J. Chem. Phys. 4, 283-291 (1936).

62. Voorhees, P. W. Ostwald ripening of two-phase mixtures. Annu. Rev. Mater. Sci. 22, 197-215 (1992).

63. Thomas, C. W. \& Asimow, P. D. Direct shock compression experiments on premolten forsterite and progress toward a consistent high-pressure equation of state for $\mathrm{CaO}-\mathrm{MgO}-\mathrm{Al}_{2} \mathrm{O}_{3}-\mathrm{SiO}_{2}-\mathrm{FeO}$ liquids. J. Geophys. Res. 118, 5738-5752 (2013).

64. Wolf, A. S., Jackson, J. M., Dera, P. \& Prakapenka, V. B. The thermal equation of state of $(\mathrm{Mg}, \mathrm{Fe}) \mathrm{SiO}_{3}$ bridgmanite (perovskite) and implications for lower mantle structures. J. Geophys. Res. 120, 7460-7489 (2015).

65. Fischer, R. A. et al. Equation of state and phase diagram of FeO. Earth Planet. Sci. Lett. 304, 496-502 (2011).

66. Liu, Z. et al. Elastic wave velocity of polycrystalline $\mathrm{Mj}_{80} \mathrm{Py}_{20}$ garnet to $21 \mathrm{GPa}$ and 2,000 K. Phys. Chem. Miner. 42, 213-222 (2015).

67. Zhang, L., Ahsbahs, H., Kutoglu, A. \& Geiger, C. Single-crystal hydrostatic compression of synthetic pyrope, almandine, spessartine, grossular and andradite garnets at high pressures. Phys. Chem. Miner. 27, 52-58 (1999).

68. Liu, W. \& Li, B. Thermal equation of state of $\left(\mathrm{Mg}_{0.9} \mathrm{Fe}_{0.1}\right)_{2} \mathrm{SiO}_{4}$ olivine. Phys. Earth Planet. Int 157, 188-195 (2006).

69. Downs, R. T., Zha, C. S., DuFFY, T. S. \& Finger, L. W. The equation of state of forsterite to $17.2 \mathrm{GPa}$ and effects of pressure media. Am. Miner. 81, 51-55 (1996).

\section{Acknowledgements}

We thank T. Yoshino, F. Xu, E. Boulard, N. Tsujino, H. Gomi, C. Zhao, Y. Zhang, M. Sakurai, V. Jaseem, and C. Oka for their assistance in high-pressure, high-temperature experiments. We thank R. Njul, D. Wiesner, D. Krauße for the help on polishing sample, measuring SEM and Microprobe, respectively. Discussions with E. Ito, M. Kanzaki, A. Suzuki, and C. Wang helped design the project, and with F. Noritake, S. Ohmura, T. Tsuchiya, X. Xue, S. Yamashita, Y. Wang, and D. Dobson improved knowledge of silicate melt. We thank J. Monteux for the discussion on the adiabats of a magma ocean, S. Karato for the discussion on fitting of the experimental data and D.J. Stevenson for the discussion on viscous drag for different flow patterns. We thank M. Izawa for the proof reading of the paper and $\mathrm{T}$. Katsura for suggestions on improving figures. The BDD powder was grinded at the Geodynamic Research Center, Ehime University under the PRIUS program with T. Irifune and T. Shinmei (Project Nos. A48, 2016-A02, 2017-A01, 2017-A21, and 2018-B30). This work was supported by JSPS Research Fellowship for Young Scientists (DC2-JP17J10966 to L. Xie) and Grants-in-Aid for Scientific Research (Nos. 22224008 and $15 \mathrm{H} 02128$ to A.Y.). This is a contribution $\mathrm{n}^{\circ} 383$ to the ClerVolc program. The in-situ falling sphere experiments were performed under SPring-8 Budding Researcher Support Program (Nos. 2015A1771, 2016A1651, 2016B1686, 2017B1686, and 2018A1637) and SOLEIL research proposals (20160333, 20170194).

\section{Author contributions}

L.X. and A.Y. designed the project. L.X. planned and performed experiments with D.A., A.Y., G.M., D.Y., Y.H., Y.T., N.G., A.K. and M. S. L.X. did the image analysis with A.K. L.X. performed the data analysis and Monte Carlo simulation. L.X., D.A. and D.Y. developed the homologous scaling model. A.Y. performed the finite element analysis for overshoot of temperature during experiments. L.X., D.A. and A.Y. developed the model of magma ocean solidification. The paper was written by L.X., A.Y. and D.A.

\section{Competing interests}

The authors declare no competing interests.

\section{Additional information}

Supplementary information is available for this paper at https://doi.org/10.1038/s41467019-14071-8.

Correspondence and requests for materials should be addressed to L.X.

Peer review information Nature Communications thanks Bijaya Karki and the other, anonymous, reviewers for their contribution to the peer review of this work. Peer reviewer reports are available.

Reprints and permission information is available at http://www.nature.com/reprints

Publisher's note Springer Nature remains neutral with regard to jurisdictional claims in published maps and institutional affiliations.

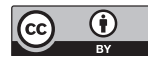

Open Access This article is licensed under a Creative Commons Attribution 4.0 International License, which permits use, sharing, adaptation, distribution and reproduction in any medium or format, as long as you give appropriate credit to the original author(s) and the source, provide a link to the Creative Commons license, and indicate if changes were made. The images or other third party material in this article are included in the article's Creative Commons license, unless indicated otherwise in a credit line to the material. If material is not included in the article's Creative Commons license and your intended use is not permitted by statutory regulation or exceeds the permitted use, you will need to obtain permission directly from the copyright holder. To view a copy of this license, visit http://creativecommons.org/ licenses/by/4.0/.

(c) The Author(s) 2020 